\title{
Association of CC chemokine ligand 5 genotype with urinary albumin excretion in the non-diabetic Japanese general population: the Takahata study
}

\author{
Tsuneo Konta $\cdot$ Mitsuru Emi $\cdot$ Sayumi Toriyama $\cdot$ Hideto Ariumi $\cdot$ Miho Ishii · \\ Satoshi Takasaki · Ami Ikeda $\cdot$ Kazunobu Ichikawa $\cdot$ Yoko Shibata $\cdot$ Noriaki Takabatake \\ Yasuchika Takeishi $\cdot$ Takeo Kato $\cdot$ Sumio Kawata $\cdot$ Isao Kubota
}

Received: 9 September 2007 / Accepted: 26 December 2007/Published online: 24 January 2008

(C) The Japan Society of Human Genetics and Springer 2008

\begin{abstract}
Albuminuria is an early marker of vascular damage, and its development in diabetic nephropathy is associated with genotype of inflammatory $\mathrm{CC}$ chemokine ligand 5 (CCL5). This study investigated whether the association of CCL5 and albuminuria is a general phenomenon. We characterized a Japanese population consisting of 2,749 non-diabetic individuals over 40 years in Takahata, Japan. The urine albumin-creatinine ratio (UACR) was obtained from morning spot urine. We genotyped SNPs within the CCL5 gene that displayed frequent minor allele frequencies in Japanese (i.e., rs2107538, rs2280789, rs3817655 and rs9909416). Assessment of possible association and linkage disequilibrium (LD) revealed that all four SNP genotypes are correlated significantly with UACR $(P=0.004-0.005)$, and these four
\end{abstract}

Sources of support: A grant-in-aid from the 21st Century Center of Excellence (COE) Program of the Japan Society for the Promotion of Science and a grant-in-aid for Scientific Research (no. 14770546)

from the Ministry of Education, Science, Sports and Culture, Japan.

T. Konta $(\bowtie) \cdot$ S. Takasaki $\cdot$ A. Ikeda $\cdot$ K. Ichikawa

Y. Shibata $\cdot$ N. Takabatake $\cdot$ Y. Takeishi - I. Kubota

Department of Cardiology, Pulmonology, and Nephrology,

Yamagata University School of Medicine,

2-2-2, Iida-Nishi, Yamagata 990-9585, Japan

e-mail: kkonta@med.id.yamagata-u.ac.jp

M. Emi · S. Toriyama $\cdot$ H. Ariumi · M. Ishii

HuBit Genomix Research Institute, Tokyo, Japan

T. Kato

Department of Neurology, Hematology, Metabolism,

Endocrinology and Diabetes,

Yamagata University School of Medicine, Yamagata, Japan

S. Kawata

Department of Gastroenterology,

Yamagata University School of Medicine, Yamagata, Japan
SNPs variations showed an obvious consistency of genotypes by detecting almost complete linkage disequilibrium $\left(D^{\prime}=1\right.$ and $\left.r^{2}>0.95\right)$. We found two exclusive haplotypes in the CCL5 gene (haplotype1: rs2107538G/ rs2280789T/rs3817655T/rs9909416G, frequency 0.64 and haplotype2: rs2107538A/rs2280789C/rs3817655A/rs99094 $16 \mathrm{~A}$, frequency 0.35 ) among the population. A significant association with elevated UACR was identified with haplotype1 $(P=0.002)$. Homozygotes for haplotype1 displayed strikingly-elevated UACR $(48.5 \pm 6.6 \mathrm{mg} / \mathrm{g}$, $n=1,116)$ compared to the rest $(28.6 \pm 1.6 \mathrm{mg} / \mathrm{g}$, $n=1,530)(P=0.001)$. In conclusion, these results suggested that genetic variation of CCL5 might be an important risk factor for albuminuria in the non-diabetic Japanese general population.

Keywords Albuminuria - Chemokine . General population · Genotype · Inflammation

\section{Introduction}

Albuminuria is an early marker of vascular damage and is widely accepted as a risk factor for progressive renal deterioration, cardiovascular morbidity and all-cause mortality (Hillege et al. 2001; Yuyun et al. 1997). Many studies have revealed that several environmental factors including diabetes, hypertension, obesity, smoking and metabolic syndrome are involved in its development (Yuyun et al. 1997).

Concerning the molecular mechanism of the development of albuminuria, there are clinical and experimental studies showing that the inflammation might be a key in renal vascular damages. Among the inflammatory cascade, TNF-alpha, interleukin-1beta and their down-stream 
molecule, $\mathrm{CC}$ chemokines such as $\mathrm{CC}$ chemokine ligand 5 (CCL5) are playing a pivotal role in glomerular injury through the induction of inflammatory cell infiltration (Schlondorff et al. 1997).

Although the environmental factors are important for the induction of vascular injury, the significance of genetic factors is also suggested by the fact that familial clustering of nephropathy was observed both in insulin-dependent and non-insulin dependent diabetes mellitus (Krolewski 1999). The search for genetic factors in the development of diabetic nephropathy was performed on several molecules such as human atrial natriuretic peptide (hANP) and angiotensin converting enzyme (ACE) (Nannipieri et al. 2001; Hadjadj et al. 2007). Nakajima et al. reported that the genotype of the promoter region of CCL5, inflammatory chemokine, is associated with the development of albuminuria in diabetic nephropathy (Nakajima et al. 2003). However, these findings were mostly obtained in diabetic nephropathy. It is largely unknown what kind of genetic properties participate in the development of albuminuria in the general population.

The relationship between SNPs and diseases depends on the ethnicity. Among the genetic properties related with diabetic nephropathy mentioned above, the relation to CCL5 was reported in the Japanese population. In addition, we have previously reported the involvement of macrophage in renal injury induced by subtotal nephrectomy (Konta et al. 1997). This suggests that the factors recruiting inflammatory cells, such as chemokines, might be involved in the progression of non-diabetic renal injury. Taken together, we focused on the genetic variation of CCL5 and examined whether the association of CCL5 and albuminuria noted in diabetic nephropathy is a general phenomenon in this study.

\section{Methods}

\section{Study population}

This study is part of the ongoing molecular epidemiological study utilizing the regional characteristics of $21 \mathrm{st}$ Century Centers of Excellence (COE) Program in Japan as previously described in detail (Konta et al. 2006). The aim of the present study is to determine the association between genetic variants and albuminuria in the general population in Japan. This study is a design-incorporated baseline survey that consisted of a self-administered questionnaire on lifestyle, blood pressure measurement, anthropometrical measurement, and collections of blood and urine specimens from participants at annual health checkup. Genomic DNA was extracted from peripheral blood samples as previously described (Yoshida et al. 2002).
The survey population in this study is the general population over 40 years old in Takahata, Japan. In 2004 and 2005, a total of 3,115 subjects (mean age 63 ; men 1,380; women 1,735 ) took part in the program and agreed to join the study. This study was approved by the institutional ethical committee. All participants gave written informed consent.

Among 3,115 subjects, 131 and 235 subjects were excluded from the present analysis due to their incomplete data and having diabetes mellitus, respectively. Thus, 2,749 subjects were entered into final analyses (mean age 63 ; men 1,234; women 1,515).

\section{Measurement}

Clinical information concerning medical history, current medication, smoking habits and alcohol intake was obtained from a self-reported questionnaire. Blood pressures were determined by using a mercury manometer in subjects who had rested in a sitting position for at least 5 min before the measurement. Hypertension was defined as systolic blood pressure $\geq 140 \mathrm{mmHg}$ and/or diastolic blood pressure $\geq 90 \mathrm{mmHg}$, and/or the use of anti-hypertensive medication. Body mass index was calculated from weight and height measures as weight $(\mathrm{kg})$ divided by the square of height $\left(\mathrm{m}^{2}\right)$. Obesity was specified as body mass index $\geq 25.0 \mathrm{~kg} / \mathrm{m}^{2}$ both in men and women. Diabetes was ascertained either by self-reported physical diagnosis or by a measure fasting blood sugar $\geq 126 \mathrm{mg} / \mathrm{dl}$ or $\mathrm{HbA} 1 \mathrm{c}$ value $\geq 6.5 \%$. The subjects with impaired glucose tolerance were included in this analysis. Hypercholesterolemia was ascertained by a measure serum total cholesterol $\geq 220 \mathrm{mg} / \mathrm{dl}$, and/or the use of anti-hyperlipidemic medication. Urine albumin-creatinine ratio (UACR) was calculated from a single spot urine specimen collected in the morning. Urine albumin concentration was determined by an immunoturbidimetry. Albuminuria was defined as UACR $\geq 20 \mathrm{mg} / \mathrm{g}$ in men and $\geq 30 \mathrm{mg} / \mathrm{g}$ in women, respectively. Microalbuminuria was defined as UACR $20-200 \mathrm{mg} / \mathrm{g}$ in men and $30-300 \mathrm{mg} / \mathrm{g}$ in women, and macroalbuminuria was defined as UACR $>200 \mathrm{mg} / \mathrm{g}$ in men and $>300 \mathrm{mg} / \mathrm{g}$ in women, respectively (Levey et al. 2005). Serum creatinine (SCr) was measured by enzymatic method, and glomerular filtration rate (GFR) was estimated using the modified MDRD equation with Japanese coefficient 0.881 (Imai et al. 2007).

SNP selection and genotyping

We utilized Haploview software version 3.32 (Barrett et al. 2005) and dbSNP database of the NCBI (http://www. 
ncbi.nlm.nih.gov/SNP/) and International HapMap Project (http://www.hapmap.org/index.html) to extract all SNPs of the CCL5 gene with a minor allele frequency greater than 0.25 in the Japanese general population. Four SNPs (rs2107538 in promoter, rs2280789 in intron 1, rs3817655 in intron 2 and rs9909416 in $3^{\prime}$ near gene) were selected and have been genotyped. All SNPs gave accurate typing (call rate $>99 \%$ ) and were used in this study.

Genotypes for these four SNPs were determined by Invader assay (Third Wave Technologies, Madison, WI) (Lyamichev et al. 1999; Mein et al. 2000) and TaqMan allelic discrimination assay (Livak 1999). Reagents were purchased from Applied Biosystems (Foster City, CA). TaqMan probes were designed and synthesized by Applied Biosystems and distinguished the SNPs at the end of a polymerase chain reaction. One allelic probe was labeled with fluorescent FAM dye and the other with the fluorescent VIC dye. Polymerase chain reaction was performed by TaqMan Universal Master Mix without UNG (Applied Biosystems) with polymerase chain reaction primers at a concentration of $900 \mathrm{nM}$ and TaqMan MGB probes at a concentration of $200 \mathrm{nM}$. Reactions were performed in 384-well formats in a total reaction volume of $3 \mu \mathrm{l}$ using $3.0 \mathrm{ng}$ of genomic DNA. The plates were then placed in a GeneAmp PCR System 9700 (Applied Biosystems) and heated at $95^{\circ} \mathrm{C}$ for $10 \mathrm{~min}$, followed by 40 cycles at $92^{\circ} \mathrm{C}$ for $15 \mathrm{~s}$ and $60^{\circ} \mathrm{C}$ for $1 \mathrm{~min}$, with a final soak at $25^{\circ} \mathrm{C}$. The plates were read by the Prism 7900HT instrument (Applied Biosystems) where the fluorescence intensity in each well of the plate was read (Livak 1999). Fluorescence data files from each plate were analyzed by the SDS 2.0 allele calling software (Applied Biosystems). Several data (signal intensity) were eliminated to preserve the reliability of the assay system (missing data are guaranteed to be less than $1 \%)$.

\section{Statistical analyses}

We used Student's $t$-test to evaluate differences in means and chi-square tests to evaluate differences in proportions. Some of the clinical and biochemical traits in each genotypic group did not distribute normally; we applied a nonparametric Mann-Whitney test or an analysis of variance (ANOVA) with linear regression analysis as a post hoc test $(P<0.05)$ to compare those traits among groups divided by a SNP. To confirm Hardy-Weinberg equilibrium among genotypes, chi-square tests were used $(P \geq 0.05)$. Linkage disequilibrium (LD) for the combination of variations was tested by $D^{\prime}$ and $r^{2}$ by using Haploview. Haplotypes were inferred and haplotype frequencies were estimated using the modified expectationmaximization (EM) method of haplotype inference included in haplo.stats program (Schaid et al. 2002). Data are expressed as mean $\pm \mathrm{SD}$ except as otherwise indicated. A significant difference was defined as $P<0.05$. All statistical analyses were performed using SPSS version 15.0.1 J (SPSS, Inc., Chicago, IL).

\section{Results}

Characteristics of subjects

Baseline characteristics of 2,749 subjects that entered into a final analysis were shown in Table 1. Overall, mean age was 63 years old. Among them, there were 1,234 men (44.9\%), 1,476 subjects $(53.7 \%)$ with hypertension, 792 subjects $(28.8 \%)$ with obesity, 924 subjects $(33.6 \%)$ with hypercholesterolemia, and 577 subjects $(21.0 \%)$ with albuminuria.

Table 1 Comparisons of baseline characteristics between men and women

\begin{tabular}{lll}
\hline & Men & Women \\
\hline Number & 1,234 & 1,515 \\
Age (years) & $63.0 \pm 10.5$ & $62.5 \pm 10.2$ \\
Systolic BP (mmHg) & $135.8 \pm 15.6$ & $132.5 \pm 16.1$ \\
Diastolic BP (mmHg) & $81.8 \pm 9.9$ & $77.3 \pm 9.8$ \\
Body mass index (kg/m²) & $23.4 \pm 2.9$ & $23.4 \pm 3.3$ \\
Hypertension (\%) & 57.1 & 51.1 \\
Obesity (\%) & 29.2 & 28.6 \\
Smoker (\%) & 62.7 & 8.2 \\
Drinker (\%) & 73.3 & 15.3 \\
Hypercholesterolemia (\%) & 24.0 & 41.3 \\
Serum creatinine (mg/dl) & $0.78 \pm 0.23$ & $0.59 \pm 0.11$ \\
Serum total cholesterol (mg/dl) & $193.5 \pm 30.3$ & $207.2 \pm 31.0$ \\
Fasting blood sugar (mg/dl) & $92.8 \pm 9.8$ & $90.3 \pm 9.8$ \\
Hemoglobin Alc (\%) & $5.08 \pm 0.40$ & $5.16 \pm 0.39$ \\
Uric acid (mg/dl) & $5.79 \pm 1.31$ & $4.47 \pm 1.06$ \\
Estimated GFR (ml/min/ & $73.6 \pm 14.4$ & $78.6 \pm 13.9$ \\
$\quad 1.73$ m ${ }^{2}$ ) & & \\
Urine creatinine (g/l) & $1.33 \pm 0.68$ & $1.02 \pm 0.53$ \\
Urine albumin (mg/l) & $7.6(1.9-$ & $10.1(2.2-$ \\
& $1,248.8)$ & $1,760.4)$ \\
UACR (mg/g) & $4.7(0.6-$ & $11.6(1.4-$ \\
Albuminuria (\%) & $2,455.7)$ & $3,592.7)$ \\
\hline Urine albumin and UACR are & 21.1 & 20.9 \\
\hline
\end{tabular}

Urine albumin and UACR are expressed as median with range (min$\max$ )

$B P$ blood pressure; GFR glomerular filtration rate 
Polymorphisms in CCL5 genes examined in this study

CCL5 gene is located on chromosome 17q11.2-q12. We have selected four SNPs regarding CCL5 genes that displayed frequent minor allele frequencies in Japanese from the dbSNP database of the NCBI and International HapMap Project as described in the Methods section. The chromosomal locations of these four SNPs are shown in Fig. 1, and their characters are summarized in Table 2.

\section{Association of single point SNPs of CCL5 with UACR}

To investigate whether CCL5 gene SNPs are involved in urinary albumin excretion, we performed quantitative trait locus (QTL) analyses of population having the SNPs and UACR by ANOVA (Fig. 2). The result of ANOVA showed that all four SNPs were significantly associated with UACR levels. The UACR levels of population having CCL5 $\mathrm{SNP}$ rs2107538 G/G, G/A and A/A were 48.1 \pm 6.5 , $29.4 \pm 2.1$, and $26.2 \pm 3.8$ (mean $\pm \mathrm{SE}$ ), respectively $(P=0.004)$. Similarly, the UACR levels of population having CCL5 SNP rs2280789 (T/T, T/C and C/C), rs3817655 (T/T, T/A and A/A), and rs2280789 (T/T, T/C and $\mathrm{C} / \mathrm{C}$ ) showed almost identical results (Table 3 ).

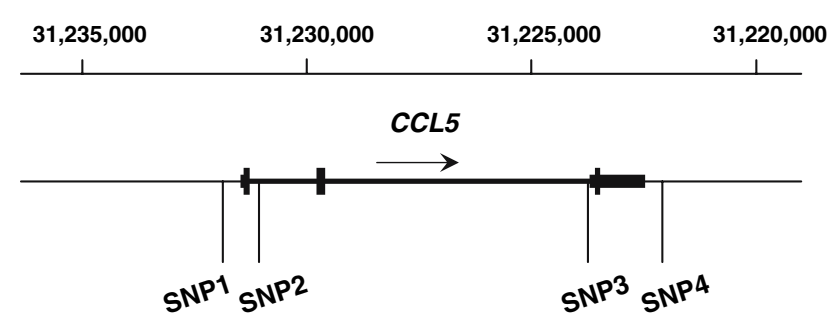

Fig. 1 The chromosomal locations of SNPs in the CCL5 gene. Coding exons are represented by thick blocks connected by bold lines representing introns. The $5^{\prime}$ and $3^{\prime}$ untranslated regions (UTRs) are displayed as thinner blocks on the leading and trailing ends of the aligning regions. SNP1; rs2107538, SNP2; rs2280789, SNP3; rs3817655, SNP4; rs9909416
Linkage disequilibrium of the CCL5 gene

To examine linkage disequilibrium (LD) of the CCL5 gene, we performed LD analysis using four SNP typing data. We observed an obvious consistency of genotypes between four of the SNPs, rs2107538 G/A, rs2280789 T/C, rs3817655 T/A and rs9909416 G/A, by detecting almost complete linkage disequilibrium $\left(D^{\prime}=1\right.$ and $\left.r^{2}>0.95\right)$ (Fig. 3, a, b, 4).

Haplotype structure and its frequencies of CCL5

Based on the finding that these two SNPs were located in a tight LD block, we examined the characteristics of CCL5 haplotypes. Estimated haplotypes and their frequencies of CCL5 are shown in Table 4. Two exclusive haplotypes showed the frequencies $>0.5 \%$ in each other and accounted for most $(99.3 \%)$ of the haplotypes associated with CCL5.

\section{Haplotype-based association of the CCL5 with UACR}

The single points of SNPs (rs2107538 G, rs2280789 T, rs3817655 $\mathrm{T}$ and rs9909416 G) were associated with higher UACR. To examine whether the haplotype block including these SNPs is associated with UACR levels, we performed haplotype-based association analyses. A significant association with elevated UACR was identified with haplotype 1, rs2107538 G/rs2280789 T/rs3817655 T/ rs9909416 G, $(P=0.002)$. Homozygotes for haplotype 1 displayed strikingly elevated UACR $(48.5 \pm 6.6 \mathrm{mg} / \mathrm{g}$, $n=1,116)$ compared to the rest $(28.6 \pm 1.6 \mathrm{mg} / \mathrm{g}$, $n=1,530$; mean $\pm \mathrm{SE} ; P=0.001)$. We performed age-, gender-, and complication-stratified analysis. It revealed that the difference in UACR levels between diplotypes was significant in elderly ( $\geq 60$ years old), hypertensive subjects, but not young or normotensive subjects (Table 5).

Further, we examined the prevalence of albuminuria in each diplotype. The prevalence of microalbuminuria

Table 2 Polymorphisms in CCL5 genes examined in the study

\begin{tabular}{|c|c|c|c|c|c|c|c|c|c|c|c|c|c|}
\hline \multirow[t]{2}{*}{ SNP ID } & \multirow[t]{2}{*}{ Gene symbol } & \multirow{2}{*}{$\begin{array}{l}\text { NCBI SNP } \\
\text { reference }\end{array}$} & \multirow[t]{2}{*}{ SNP type } & \multirow[t]{2}{*}{ Chr } & \multirow{2}{*}{$\begin{array}{l}\text { Public location } \\
\text { position (B36.2) }\end{array}$} & \multicolumn{2}{|c|}{ Allele } & \multicolumn{2}{|c|}{ Allele frequency } & \multicolumn{3}{|c|}{ Genotype } & \multirow[t]{2}{*}{ Heterozygosity } \\
\hline & & & & & & 1 & 2 & Allele 1 & Allele 2 & 11 & 12 & 22 & \\
\hline SNP1 & CCL5 & rs2107538 & promoter -403 & 17 & 31231893 & G & A & 0.64 & 0.36 & 1,135 & 1,244 & 357 & 0.46 \\
\hline SNP2 & CCL5 & rs2280789 & Intron_1 & 17 & 31231115 & $\mathrm{~T}$ & $\mathrm{C}$ & 0.65 & 0.35 & 1,156 & 1,235 & 342 & 0.456 \\
\hline SNP3 & CCL5 & rs3817655 & Intron_2 & 17 & 31223753 & $\mathrm{~T}$ & A & 0.65 & 0.35 & 1,156 & 1,222 & 357 & 0.457 \\
\hline SNP4 & CCL5 & rs9909416 & $3^{\prime}$ near gene & 17 & 31222096 & G & A & 0.65 & 0.35 & 1,154 & 1,223 & 334 & 0.45 \\
\hline
\end{tabular}

Typing call rates were over 99\%. The Hardy-Weinberg equilibrium $P$-values were not deviated in all SNPs $(P>0.1)$

NCBI National Center for Biotechnology Information, Allele 1 major allele, Allele 2 minor allele, CCL5 chemokine (C-C motif) ligand 5, Chr chromosome 
Fig. 2 Association of single point SNPs of CCL5 with UACR. UACR was expressed as mean \pm SE. $P$ value shows the comparison among three single point SNPs by ANOVA with linear regression analysis as a post hoc test. $N S$ not significant
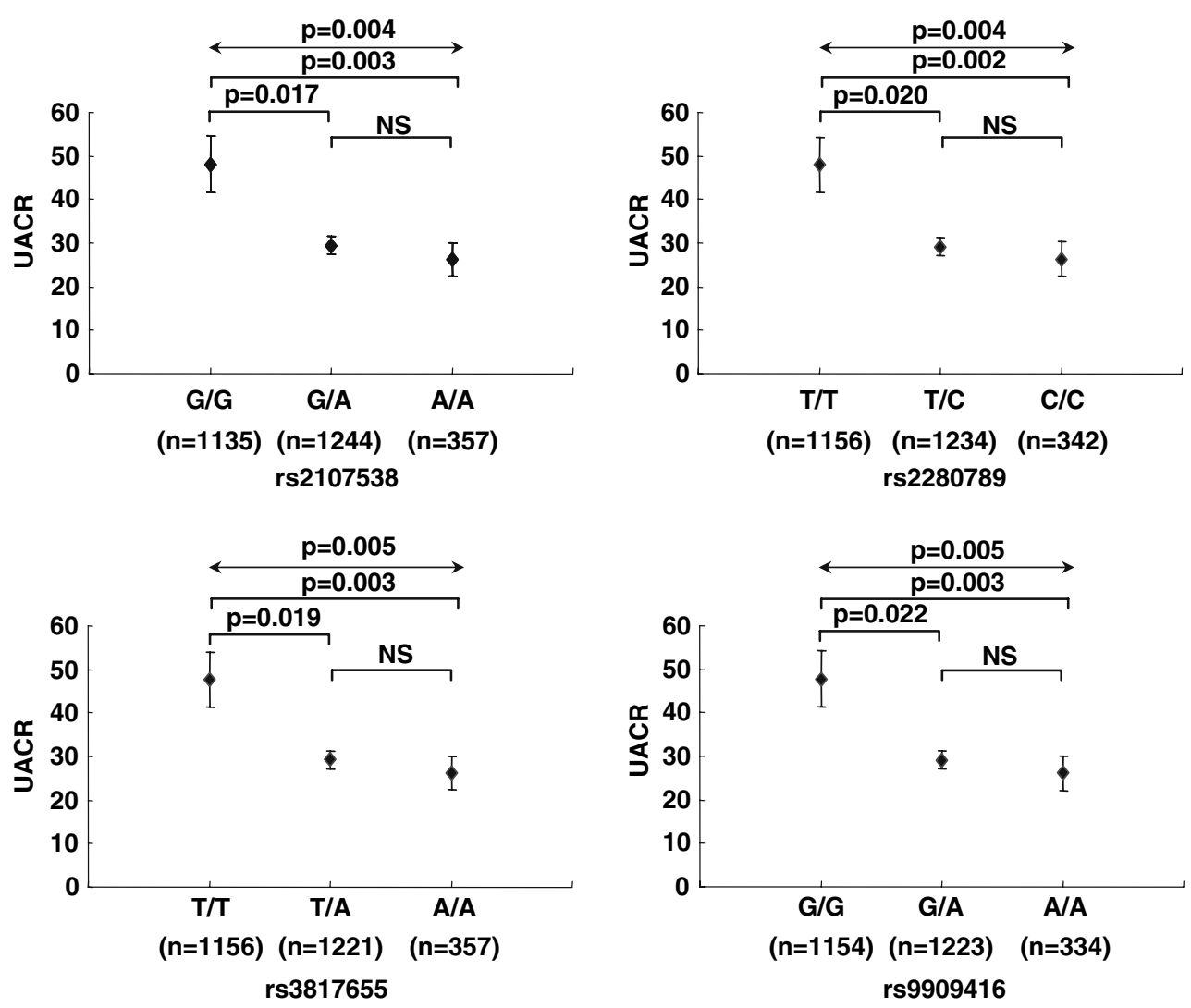

Table 3 The association analysis of each SNP examined in the study with the UACR using parametric measure

\begin{tabular}{|c|c|c|c|c|c|c|c|c|c|c|c|}
\hline \multirow{2}{*}{$\begin{array}{l}\text { SNP } \\
\text { ID }\end{array}$} & \multirow{2}{*}{$\begin{array}{l}\text { NCBI } \\
\text { reference } \\
\text { ID }\end{array}$} & \multirow{2}{*}{$\begin{array}{l}\text { ANOVA } \\
P \text { value }\end{array}$} & \multicolumn{3}{|c|}{ Post-hock (LSD) $P$ value } & \multicolumn{3}{|l|}{ Mean $\pm \mathrm{SE}$} & \multicolumn{3}{|c|}{ Genotype } \\
\hline & & & $\begin{array}{l}11 \\
\text { versus } \\
12\end{array}$ & $\begin{array}{l}11 \\
\text { versus } \\
22\end{array}$ & $\begin{array}{l}12 \\
\text { versus } \\
22\end{array}$ & 11 & 12 & 22 & 11 & 12 & 22 \\
\hline SNP1 & rs 2107538 & 0.004 & 0.003 & 0.017 & NS & $48.1 \pm 6.5$ & $29.4 \pm 2.1$ & $26.2 \pm 3.8$ & $\mathrm{G} / \mathrm{G}$ & G/A & $\mathrm{A} / \mathrm{A}$ \\
\hline SNP2 & rs 2280789 & 0.004 & 0.002 & 0.020 & NS & $48.0 \pm 6.4$ & $29.1 \pm 2.1$ & $26.3 \pm 3.9$ & $\mathrm{~T} / \mathrm{T}$ & $\mathrm{T} / \mathrm{C}$ & $\mathrm{C} / \mathrm{C}$ \\
\hline SNP3 & rs3817655 & 0.005 & 0.003 & 0.019 & NS & $47.7 \pm 6.4$ & $29.3 \pm 2.1$ & $26.2 \pm 3.8$ & $\mathrm{~T} / \mathrm{T}$ & T/A & $\mathrm{A} / \mathrm{A}$ \\
\hline SNP4 & rs9909416 & 0.005 & 0.003 & 0.022 & NS & $47.8 \pm 6.4$ & $29.1 \pm 2.1$ & $26.2 \pm 4.0$ & $\mathrm{G} / \mathrm{G}$ & G/A & $\mathrm{A} / \mathrm{A}$ \\
\hline
\end{tabular}

NCBI National Center for Biotechnology Information, Allele 1 major allele, Allele 2 minor allele, CCL5 chemokine (C-C motif) ligand 5, NS not significant

(UACR 20-200 mg/g in men and 30-300 mg/g in women) and macroalbuminuria (UACR $>200 \mathrm{mg} / \mathrm{g}$ in men and $>300 \mathrm{mg} / \mathrm{g}$ in women) was not significantly different between homozygotes for haplotype 1 (18.6 and 2.6\%) and the remaining diplotypes (20.0 and 1.8\%; Table 5).

\section{Discussion}

In this study the association between CCL5 genotype and albuminuria noted in diabetic patients was confirmed in the non-diabetic general population. This result suggests that genetic variation of CCL5 might be a common factor for the development of albuminuria.
Familial clustering of diabetic nephropathy has been reported in many studies, and genetic background for diabetic nephropathy is a current interest. Recent research on the susceptibility genes of diabetic nephropathy has revealed that the development of albuminuria was related with the genotypes of several genes including hANP (Nannipieri et al. 2001), ACE (Hadjadj et al. 2007), the solute carrier family 12 (SLC12A3) (Nishiyama et al. 2005), the engulfment and cell motility 1 (ELMO1) (Shimazaki 2005), lipoprotein lipase (Mattu et al. 2002), and CCL5/RANTES (Nakajima et al. 2003). However, whether these relationships are also observed in non-diabetic general population has been unknown. In this study, we have revealed for the first time that genetic variants of CCL5 
Fig. 3 Linkage disequilibrium (LD) analysis of four SNPs in CCL5, as measured by $D^{\prime}$ (a) and $r^{2}(\mathbf{b})$. Dark squares signify high $D$ values. SNP1; rs2107538, SNP2; rs2280789, SNP3; rs3817655, SNP4; rs9909416
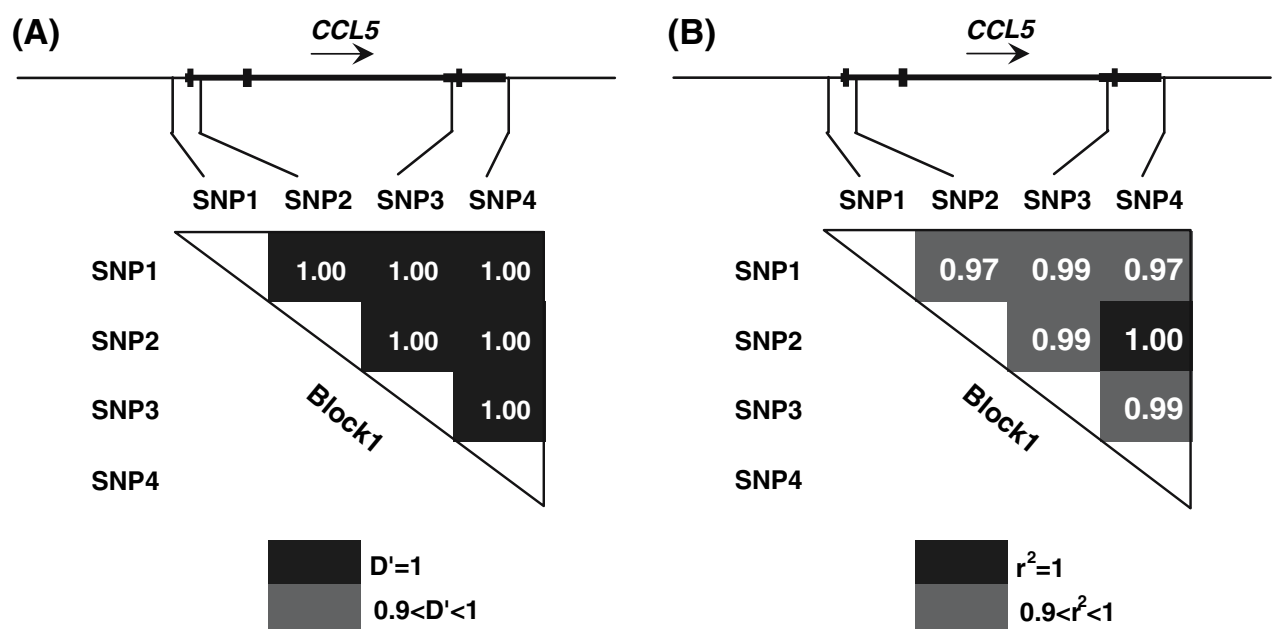

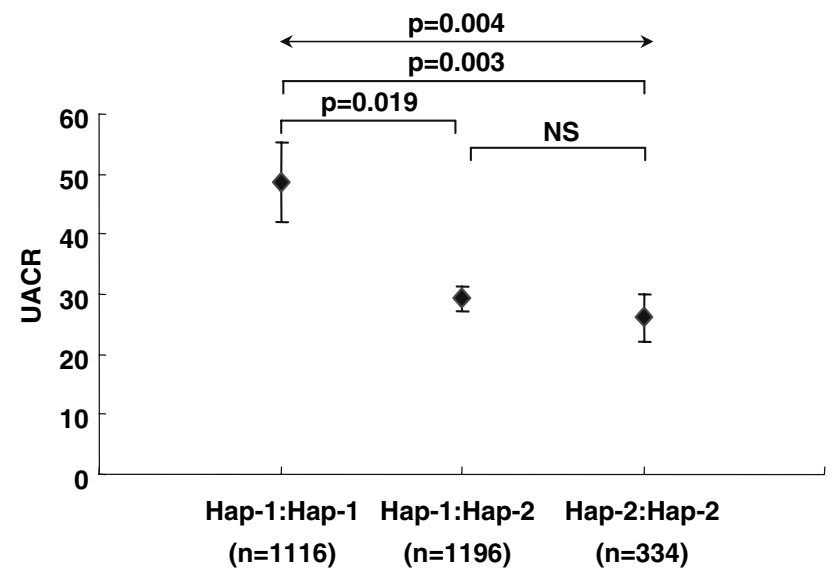

Fig. 4 Haplotype-based association of the CCL5 with UACR. UACR was expressed as mean \pm SE. $P$ value shows the comparison among three single point SNPs by ANOVA with linear regression analysis as a post hoc test. Hap-1; haplotype 1, rs2107538G/rs2280789T/rs381 7655T/rs9909416G, Hap-2; haplotype 1, rs2107538A/ rs2280789C/ rs3817655A/rs9909416A. NS not significant

might play a role in the initial step of non-diabetic glomerular damage. This finding seems to be clinically important because it suggests that there is a large number of genetically high-risk subjects for vascular events among the general population.

It is quite interesting that immunomodulating and inflammatory chemokine CCL5 has a relation to albuminuria in the non-diabetic population as well as the diabetic population. The involvement of CCL5 has been reported in renal development, renal transplant rejection, and HIV-associated nephropathy (Schlondorff et al. 1997). Our result suggests that CCL5 might be a common genetic factor in the induction of glomerular damage and participates in the various types of renal diseases, possibly by modulating immune response and/or inflammation.

However, the role of CCL5 in the development of albuminuria is little understood. Expression of CCL5 is observed on the endothelial surface and extracellular matrix. It recruits macrophage and $\mathrm{T}$ cells through binding CCR5 receptor of leukocytes and facilitates migration of these leukocytes to inflammatory lesions (Segerer et al. 2007). It seems to be possible that the genetic variation of the CCL5 gene might induce the change of its pathophysiological function of CCL5 and further affects the course in inflamed tissue. In diabetic nephropathy, genotypes of CCR5, a counterpart receptor of CCL5, also had a relation to albuminuria (Mokubo et al. 2006). This suggests that the glomerular vascular injury through CCL5-CCR5 interaction might be regulated by their genetic variations.

In this nondiabetic general population, the prevalence of albuminuria (UACR $\geq 30 \mathrm{mg} / \mathrm{g} ; 18.1 \%$ ), UACR levels $(34.9 \pm 2.7 \mathrm{mg} / \mathrm{g}$, mean $\pm \mathrm{SE})$, serum creatinine $(0.68 \pm 0.01 \mathrm{mg} / \mathrm{dl}$, mean $\pm \mathrm{SE})$ were lower than those in

Table 4 UACR association with major CCL5 haplotypes

\begin{tabular}{|c|c|c|c|c|c|c|c|}
\hline \multicolumn{5}{|c|}{ Haplotypes } & \multirow[t]{3}{*}{ Frequencies } & \multirow{3}{*}{$\begin{array}{l}\text { Haplotype-specific } \\
\text { score statistic }\end{array}$} & \multirow[t]{3}{*}{$P$-value } \\
\hline & SNP1 & SNP2 & SNP3 & SNP4 & & & \\
\hline & rs 2107538 & rs2280789 & rs3817655 & rs9909416 & & & \\
\hline Hap-1 & $\mathrm{G}$ & $\mathrm{T}$ & $\mathrm{T}$ & $\mathrm{G}$ & 0.643 & 3.070 & 0.002 \\
\hline Hap-2 & A & $\mathrm{C}$ & A & A & 0.350 & -3.053 & 0.002 \\
\hline \multicolumn{2}{|c|}{ Global score statistics } & \multicolumn{2}{|c|}{ Global statistics 9.45} & $d f=2$ & \multicolumn{2}{|c|}{ Global $P$-value $=0.009$} & \\
\hline
\end{tabular}

Haplotypes whose frequency exceeds $5 \%$ are listed 
Table 5 Haplotype-based association of CCL5 with UACR in subgroups

\begin{tabular}{llll}
\hline & Hap1/Hap1 & $\begin{array}{l}\text { Hap1/Hap2, } \\
\text { Hap2/Hap2 } \\
n=1,530\end{array}$ & $P$ value \\
\hline UACR $(\mathrm{mg} / \mathrm{g})$ & $n=1,116$ & & \\
Total $(n=2,646)$ & $48.5 \pm 6.6$ & $28.6 \pm 1.6$ & 0.001 \\
Men $(n=1,187)$ & $49.0 \pm 9.9$ & $27.1 \pm 2.9$ & 0.017 \\
Women $(n=1,459)$ & $48.2 \pm 8.9$ & $29.8 \pm 2.5$ & 0.023 \\
40-59 years & $22.9 \pm 6.0$ & $18.1 \pm 1.7$ & $\mathrm{NS}$ \\
$\quad(n=986)$ & & & \\
$\geq 60$ years & & & \\
$\quad(n=1,660)$ & $63.0 \pm 9.7$ & $35.1 \pm 2.8$ & 0.002 \\
HTN $(+)(n=1,428)$ & $74.9 \pm 11.7$ & $39.0 \pm 3.3$ & 0.001 \\
HTN $(-)(n=1,218)$ & $15.2 \pm 1.2$ & $17.0 \pm 1.3$ & NS \\
Microalbuminuria & $18.6 \%$ & $20.0 \%$ & NS \\
Macroalbuminuria & $2.6 \%$ & $1.8 \%$ & NS \\
\hline UACR are expressed & & &
\end{tabular}

UACR are expressed as mean $\pm \mathrm{SE}$

Microalbuminuria was defined as UACR $20-200 \mathrm{mg} / \mathrm{g}$ in men and $30-300 \mathrm{mg} / \mathrm{g}$ in women, and macroalbuminuria was defined as UACR $>200 \mathrm{mg} / \mathrm{g}$ in men and $>300 \mathrm{mg} / \mathrm{g}$ in women, respectively Hap1 haplotype1 (rs2107538G/rs2280789T/rs3817655T/rs9909416 G), Hap2 haplotype2 (rs2107538A/rs2280789C/rs3817655A/rs990 9416A), HTN hypertension, NS not significant

the diabetic population reported by Nakajima et al. (albuminuria $42.3 \%$, UACR $268.0 \pm 36.8 \mathrm{mg} / \mathrm{g}, \quad$ serum creatinine $0.78 \pm 0.01 \mathrm{mg} / \mathrm{dl})$. The prevalence of hypertension in this study was higher (54\%) than that in the diabetic population $(41 \%)$. This indicates that CCL5 genotype might have an effect on urinary albumin excretion even in the population with low-grade renal damage. However, it has been shown that a slight elevation of UACR significantly increases the risk for renal and cardiovascular complications, and lowering the cutpoint of abnormal UACR levels is recommended (Ruggenenti et al. 2006). Thus, a slight but significant increase of UACR should not be underestimated.

The difference in UACR levels between diplotypes was significant in elderly and hypertensive subjects, but not in young or normotensive subjects. Furthermore, the prevalence of micro- and macroalbuminuria were not significantly different between homozygotes for haplotype 1 and remaining diplotypes. The CCL5 genotype affects the levels of UACR, but not the prevalence of albuminuria, and its effect was apparent in the subjects with risk factors. These findings suggest that CCL5 might play a role as not an initiator, but as an aggravating factor in the development of albuminuria.

Although our results suggest the possible link between CCL5 genotypes and albuminuria in the non-diabetic population, this is based on the cross-sectional observation.
To confirm the causality between CCL5 gene and albuminuria, a longitudinal study is necessary. Further, to assess the clinical impact of this result, the incidence of renal and cardiovascular events should be followed. These points are future interests.

There are several limitations to this study. First, we have not confirmed whether the examined haplotype modulate the function of CCL5 in vivo. However, it has been revealed that the promoter SNPs is related with CCL5 expression (Nakajima et al 2003). Therefore, there is a possibility that the haplotype examined in this study is involved in the regulation of CCL5 expression. Second, we have examined UACR once. Thus, a transient increase of UACR might distort the relationship between UACR and CCL5 genotypes.

In conclusion, our results revealed that genetic variation of CCL5 might be an important risk factor for albuminuria in the non-diabetic Japanese general population. This might become a clue to explore the common mechanism in the development of albuminuria independent of the types of initial insults.

\section{References}

Barrett JC, Fry B, Maller J, Daly MJ (2005) Haploview: analysis and visualization of LD and haplotype maps. Bioinformatics 21:263265

Hadjadj S, Tarnow L, Forsblom C, Kazeem G, Marre M, Groop PH, Parving HH, Cambien F, Tregouet DA, Gut IG, Theva A, Gauguier D, Farrall M, Cox R, Matsuda F, Lathrop M, HagerVionnet N, EURAGEDIC (European Rational Approach for Genetics of Diabetic Complications) Study Group (2007) Association between angiotensin-converting enzyme gene polymorphisms and diabetic nephropathy: case-control, haplotype, and family-based study in three European populations. J Am Soc Nephrol 18:1284-1291

Hillege HL, Janssen WM, Bak AA, Diercks GF, Grobbee DE, Crijns HJ, Van Gilst WH, De Zeeuw D, De Jong PE, Prevend Study Group (2001) Prevend Study Group: microalbuminuria is common, also in a non-diabetic, nonhypertensive population, and an independent indicator of cardiovascular risk factors and cardiovascular morbidity. J Intern Med 249:519-526

Imai E, Horio M, Nitta K, Yamagata K, Iseki K, Hara S, Ura N, Kiyohara Y, Hirakata H, Watanabe T, Moriyama T, Ando Y, Inaguma $\mathrm{D}$, Narita I, Iso $\mathrm{H}$, Wakai $\mathrm{K}$, Yasuda $\mathrm{Y}$, Tsukamoto $\mathrm{Y}$, Ito S, Makino H, Hishida A, Matsuo S (2007) Estimation of glomerular filtration rate by the MDRD study equation modified for Japanese patients with chronic kidney disease. Clin Exp Nephrol 11:41-50

Konta T, Degawa N, Kato S, Tomoike H (1997) Role of transforming growth factor-beta1 during glomerulosclerosis in rats with reduced renal mass. Clin Exper Nephrol 194:187-194

Konta T, Hao Z, Abiko H, Ishikawa M, Takahashi T, Ikeda A, Ichikawa K, Takasaki S, Kubota I (2006) Prevalence and risk factor analysis of microalbuminuria in Japanese general population: the Takahata study. Kidney Int 70:751-756

Krolewski AS (1999) Genetics of diabetic nephropathy: evidence for major and minor gene effects. Kidney Int 55:1582-1596

Levey AS, Eckardt KU, Tsukamoto Y, Levin A, Coresh J, Rossert J, De Zeeuw D, Hostetter TH, Lameire N, Eknoyan G (2005) 
Definition and classification of chronic kidney disease: a position statement from kidney disease: improving global outcomes (KDIGO). Kidney Int 67:2089-2100

Livak KJ (1999) Allelic discrimination using fluorogenic probes and the $5^{\prime}$ nuclease assay. Genet Anal 14:143-149

Lyamichev V, Mast AL, Hall JG, Prudent JR, Kaiser MW, Takova T, Kwiatkowski RW, Sander TJ, de Arruda M, Arco DA, Neri BP, Brow MA (1999) Polymorphism identification and quantitative detection of genomic DNA by invasive cleavage of oligonucleotide probes. Nat Biotechnol 17:292-296

Mattu RK, Trevelyan J, Needham EW, Khan M, Adiseshiah MA, Richter D, Murray RG, Betteridge DJ (2002) Lipoprotein lipase gene variants relate to presence and degree of microalbuminuria in Type II diabetes. Diabetologia 45:905-913

Mein CA, Barratt BJ, Dunn MG, Siegmund T, Smith AN, Esposito L, Nutland S, Stevens HE, Wilson AJ, Phillips MS, Jarvis N, Law S, de Arruda M Todd JA (2000) Evaluation of single nucleotide polymorphism typing with invader on PCR amplicons and its automation. Genome Res 10:330-343

Mokubo A, Tanaka Y, Nakajima K, Watada H, Hirose T, Kawasumi M, Sakai K, Kanazawa A, Maeda S, Hosokawa K, Atsumi Y, Matsuoka K, Kawamori R (2006) Chemotactic cytokine receptor 5 (CCR5) gene promoter polymorphism $(59029 \mathrm{~A} / \mathrm{G})$ is associated with diabetic nephropathy in Japanese patients with type 2 diabetes: a 10-year longitudinal study. Diabetes Res Clin Pract 73:89-94

Nakajima K, Tanaka Y, Nomiyama T, Ogihara T, Ikeda F, Kanno R, Iwashita N, Sakai K, Watada H, Onuma T, Kawamori R (2003) RANTES promoter genotype is associated with diabetic nephropathy in type 2 diabetic subjects. Diabetes Care 26:892898

Nannipieri M, Manganiello M, Pezzatini A, De Bellis A, Seghieri G, Ferrannini E (2001) Polymorphisms in the hANP (human atrial natriuretic peptide) gene, albuminuria, hypertension. Hypertension 37:1416-1422
Nishiyama K, Tanaka Y, Nakajima K, Mokubo A, Atsumi Y, Matsuoka $K$, Watada $H$, Hirose $T$, Nomiyama $T$, Maeda $S$, Kawamori R (2005) Polymorphism of the solute carrier family 12 (sodium/chloride transporters) member 3, SLC12A3, gene at exon 23 (+78 G/A: Arg913Gln) is associated with elevation of urinary albumin excretion in Japanese patients with type 2 diabetes: a 10-year longitudinal study. Diabetologia 48:13351338

Ruggenenti P, Remuzzi G (2006) Time to abandon microalbuminuria? Kidney Int 70:1214-1222

Schaid DJ, Rowland CM, Tines DE, Jacobson RM, Poland GA (2002) Score tests for association between traits and haplotypes when linkage phase is ambiguous. Am J Hum Genet 70:425-434

Schlondorff D, Nelson PJ, Luckow B, Banas B (1997) Chemokines and renal disease. Kidney Int 51:610-621

Segerer S, Djafarzadeh R, Grone HJ, Weingart C, Kerjaschki D, Weber C, Kungl AJ, Regele H, Proudfoot AE, Nelson PJ (2007) Selective binding and presentation of CCL5 by discrete tissue microenvironments during renal inflammation. J Am Soc Nephrol 18:1835-1844

Shimazaki A, Kawamura Y, Kanazawa A, Sekine A, Saito S, Tsunoda T, Koya D, Babazono T, Tanaka Y, Matsuda M, Kawai K, Iiizumi T, Imanishi M, Shinosaki T, Yanagimoto T, Ikeda M, Omachi S, Kashiwagi A, Kaku K, Iwamoto Y, Kawamori R, Kikkawa R, Nakajima M, Nakamura Y, Maeda S (2005) Genetic variations in the gene encoding ELMO1 are associated with susceptibility to diabetic nephropathy. Diabetes 54:1171-1178

Yoshida S, Harada H, Nagai H, Fukino K, Teramoto A, Emi M (2002) Head-to-head juxtaposition of Fas-associated phosphatase-1 (FAP-1) and c-Jun NH2-terminal kinase 3 (JNK3) genes: genomic structure and seven polymorphisms of the FAP-1 gene. J Hum Genet 47:614-619

Yuyun MF, Adler AI, Wareham NJ (1997) What is the evidence that microalbuminuria is a predictor of cardiovascular disease events? Curr Opin Nephrol Hypertens 14:271-276 